\title{
Pathology of cutaneous blastomycosis in a cat
}

\author{
Vetnizah Juniantito $^{1, *}$, Eva Harlina ${ }^{1}$, Jumari $^{2}$, Vici Eko Handayani ${ }^{3}$, Iis Ismawati ${ }^{3}$ \\ ${ }^{1}$ Division of Pathology, Department of Veterinary Clinic, Reproduction, and Pathology, Faculty of Veterinary Medicine, \\ IPB University, Bogor \\ ${ }^{2}$ Program of Veterinary Profession Education, Faculty of Veterinary Medicine, Bogor Agricultural University, Bogor \\ ${ }^{3}$ Citra Pet and Vet Animal Clinic, Bekasi
}

\begin{abstract}
Cats are common as pet animals in Indonesia and live in close vicinity of human neighborhood, which make them potential for transmitting diseases to human. Blastomycosis is infectious disease caused by Blastomyces spp yeast. Here we describe morphopathology of blastomycosis found in skin of a Persian Cat. Grossly, the lesion were characterized by ulcerated wounds and multiple subcutaneous small nodules (2-5 mm in diameter) in the base of tail. Skin biopsy was made and further processed for histopathology. Microscopically, the lesion consist of epidermal necrosis, dermatitis, with coalescing dermal granulomatous inflammation, characterized by epitheloid and foreign type giant cells infiltrates. Numerous sphericalshaped structures and pseudohyphae which are Periodic Acid Schiff (PAS)-positive consistent with yeast morphology were found within the granulomas; morphology is also consistent with Blastomyces spp yeasts. Conclusively, multiple granulomatous dermatitis with evidence of Blastomyces yeasts is a hallmark of cutaneous blastomycosis. Exposure to Blastomyces spp yeast may possess infection threat to pet owners.
\end{abstract}

Keywords:

cat, blastomycosis, skin, granuloma

\section{- INTRODUCTION}

High populations of cats living in close proximity to human particulary in densely populated city like Jakarta, offer serious threats of zoonotic or opportunistic infections to human due to their role as carrier (Baker, 2018). One of the disease in both human and animals is mycoses that caused by numerous species of pathogenic yeasts and molds (Gross et al. 2005). Blastomycosis due to infection of Blastomyces spp yeasts is systemic and local mycosis that disseminate particularly to the skin; Blastomyces dermatitidis is a common causative agent (Jankovsky and Donnell 2014; Duangkaew et al. 2017). Blastomycosis is endemic in American and Asian Continents and many cases have been reported in Middle East, South Asia, and Southeast Asia (Duangkaew et al. 2017). The lungs is commonly affected by systemic blastomycosis with or without skin involvement (Gross et al. 2005; Duangkaew et al. 2017).

Pathological characteristic of this case is scattered pyogranulomatus nodules in affected tissue, particularly in lungs and skin with spherical or rounded yeats, aseptate pseudohyphae, admixed with variable infiltration of inflammatory cells such as lymphocytes, plasma cells, neutrophils and macrophages (Gross et al. 2005; Jankovsky and Donnell 2014; Duangkaew et al. 2017). To the author's knowledge there has been no reported case of feline cutaneous blastomycosis in Indonesia.

\section{- CASE DESCRIPTION}

Gross examination in the skin mass (Fig. 1) indicated a firm bulging mass ( $4 \mathrm{~cm}$ in diameter) in the base of tail with superficial multiple acute ulcerated wounds. Following incision, the mass were consisted of multiple small, $2-5 \mathrm{~mm}$ in diameter, yellowish firm subcutaneous nodules resemble to granuloma.
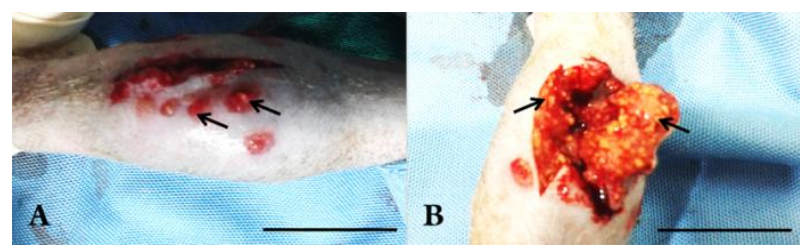

Figures 1. Multifocal ulcerated wounds in the swelling part of tail (A; arrows). Cross sectional view of tail mass revealed numerous yellowish granulomatous nodules (B; arrows). $B a r=3 \mathrm{~cm}$.

Skin biopsy samples (code S/190/14) were collected from swelling in the tail base of a 6-month-old female Persian cat. The cat showed no significant symptoms. Specimens were fixed in $10 \%$ buffered-neutral-formalin for 24 hours, which processed in graded alcohol concentrations and $\mathrm{xy}$ lene, embedded in paraffin, then routinely stained with Hematoxylin-Eosin (HE) and Periodic-Acid-Schiff (PAS) for. Any histomorphometry measurement was made in ImageJ

Received: 21-12-2019 | Revised: 14-01-2020 | Accepted: 20-01-2020

(C) 2020 CC-BY-SA. This is an Open Access article that is distributed under the terms of Creative Commons Attribution ShareAlike 4.0 International License (https://creativecommons.org/licenses/by-sa/4.0/). 
software (https://imagej.nih.gov/ij/; Bethesda, Maryland, USA).

The histopathology results revealed thickened dermis, hyperkeratosis, discontinuous epidermis indicating ulcerations, and marked infiltration of inflammatory cells predominated by macrophages (epithelioid and multiple nuclei giant cells), lymphocytes, and plasma cells, and occasional neutrophils in the dermis. Inflammatory cells admixed with lightly-stained spherical-shaped structures with single- or double-contoured walls, some organisms with broad-based budding morphology, twisted sausage-like fungal hyphae, random central necrosis, and surrounding fibrosis in HEstained sections characterized nodular granulomatous inflammation by yeast infections (Fig. 2a and b). Sphericalshaped structures and hyphae were also stained positively with PAS (Fig. 2c), indicating similar polysaccharides to yeast and pseudohyphae cell walls (Gross et al. 2005; Duangkaew et al. 2017). Additionally, spherical-shaped organisms were located free in granuloma and also found within macrophages cytoplasm (Fig. 2d). Morphological measurement of yeast organism with Image $\mathbf{J}$ software ranged from 7 to $20 \mu \mathrm{m}^{2}$. These results, particularly histopathology and yeast size, indicate consistent and typical morphologic features with Blastomyces spp organisms described elsewhere (Gross et al. 2005; Jankovsky and Donnell 2014; Duangkaew et al. 2017).

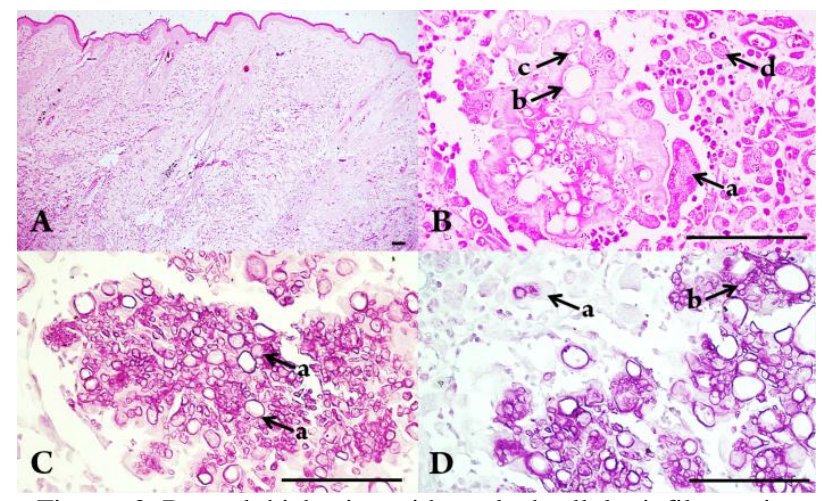

Figures 2. Dermal thickening with marked cellular infiltrates in dermis indicating dermatitis (A). Granulomatous nodule with giant cells (B; arrow a), a double-contoured yeast cell wall (B; arrow b), broad-based budding yeast (B; arrow c), with epithelioid cells (B; arrow d). PAS-stained sections showed purplish PAS-positive

Blastomyces spp yeasts (C; arrow a). Intracytoplasmic Blastomyces spp yeasts in a macrophage ( $\mathrm{D}$; arrow a) and PAS-positive pseudohyphae within granuloma (D; arrow b). HE-stained sections (A,B). PAS-stained sections $(C, D)$. Bar $=50 \mu \mathrm{m}$.

\section{- DISCUSSION}

Histopathological observation has been a gold standard for diagnosing blastomycosis because fungal culture is not recommended due to opportunistic infection via airborne route, particularly to laboratory worker (Gross et al. 2005). Differential diagnosis of blastomycosis are histoplasmosis, cryptococcosis, and coccidioidomycosis; however, blastomycosis easily recognized from its morphology such as lacks of outer capsule, broad-based rather than narrowbased budding, spherical form with double wall, and located both inside and outside macrophages, and variable 8-20 $\mu \mathrm{m}^{2}$ in yeast size (Gross et al. 2005; Jankovsky and Donnell 2014). There is potential opportunistic infection to human via direct contact or airborne routes (Gross et al. 2005; Jankovsky and Donnell 201).

\section{- CONCLUSION}

Conclusively, gross and histopathological observations in the present case indicate multiple cutaneous granulomatous dermatitis due to Blastomyces spp infection.

\section{口 AUTHOR INFORMATION}

\section{Corresponding Author}

*VJ: vetnizahju@apps.ipb.ac.id

Division of Pathology, Department of Veterinary Clinic, Reproduction, and Pathology, Faculty of Veterinary Medicine, Bogor Agricultural University, Jl. Agathis, Kampus FKH IPB Dramaga, Lt. 1 Wing 6 \& 7, Bogor-16680, West Java, INDONESIA

\section{Author Contributions}

The manuscript was written through the contributions of all authors. All authors have approved to the final version of the manuscript.

\section{- REFERENCES}

Barker A. 2018. Jakarta has a serious cat problem, containing it is dirty work.. ABC News. https://www.abc.net.au/news/2018-03-19/insidejakartas-battle-to-control-feral-cats/9541636

Duangkaew L, Larsuprom L, Kasondorkbua C, Chen C, Chindamporn A. 2017. Cutaneous blastomycosis and dermatophytic pseudomycetoma in a Persian cat from Bangkok, Thailand. Medical Mycology Case Reports. 15: 12-15.

Gross TL. Ihrke PJ, Walder EJ, Affolter VK. 2005. Skin diseases of a dog and cat. Blackwell Science.

Jankovsky JL, Donnell RL. 2014. Blastomyces dermatitidis pneumonia in a Ilama. Journal of Veterinary Diagnostic Investigation. 30(4): 576-579. 